\title{
The Impact of Tobacco Taxation Policy on Slim Cigarette Use and the Growing Popularity of Slim Cigarettes in China Since 2014
}

\author{
Xiulan Zhang1, Xiaoxin $\mathrm{Xu}^{1 *}$, Mengnan $\mathrm{Xu}^{1}$, Teh-wei $\mathrm{Hu}^{2}$ \\ ${ }^{1}$ School of Social Development and Public Policy, Beijing Normal University, Beijing, China \\ ${ }^{2}$ School of Public Health, University of California, Berkeley, CA, USA \\ Email: *xuxiaoxin@bnu.edu.cn
}

How to cite this paper: Zhang, X.L., Xu, X.X., Xu, M.N. and Hu, T.-w. (2019) The Impact of Tobacco Taxation Policy on Slim Cigarette Use and the Growing Popularity of Slim Cigarettes in China Since 2014. Health, 11, 711-720.

https://doi.org/10.4236/health.2019.116059

Received: March 15, 2019

Accepted: June 8, 2019

Published: June 11, 2019

Copyright $\odot 2019$ by author(s) and Scientific Research Publishing Inc. This work is licensed under the Creative Commons Attribution International License (CC BY 4.0).

http://creativecommons.org/licenses/by/4.0/

\begin{abstract}
Introduction: In 2016, China became the largest market for slim cigarettes in the world, selling 68.945 billion sticks. The purpose of this study is to examine the impact of China's 2015 tobacco taxation policy on slim cigarette consumption and the product's market trends. Methods: Monthly data on the market share of slim cigarettes and their average price between January 2014 and June 2017 were used to show tobacco market trends and to estimate the impact of the 2015 tobacco tax increase on tobacco consumption. Segmented regression analysis was used to estimate the immediate effect of the 2015 tax policy and the time trends in consumption due to the policy change. Findings: After the tobacco tax increase was announced in May 2015, the market share of slim cigarettes initially decreased by $0.2117(\mathrm{p}=0.067)$. However, by the third month after the policy change, consumption began to increase, and the market share of slim cigarettes was 1.6 times the normal increase over time. Slim cigarettes gained a $2.02 \%$ additional share by the second quarter of 2017 (from $2.58 \%$ to $4.60 \%$ ), controlling for the price difference between slim cigarettes and regular cigarettes. The coefficient of the share and the price ratio (slim cigarettes/regular cigarettes) was $-0.7536(\mathrm{p}=$ 0.0044 ), suggesting that slim cigarettes are a substitute for regular cigarettes. Estimates also show that after the tax increase was implemented, consumption of slim cigarettes increased almost three times the normal consumption rate $(0.0069$ versus 0.0024$)$. Conclusion: The slim cigarette industry in China has grown rapidly in recent years. The 2015 tax increase has had only minimal or short-term impact on reducing the growing popularity of slim cigarettes. Since slim cigarettes are a substitute for regular cigarettes, more empirical research is urgently needed to study the health impacts of slim cigarette use and the impact of tobacco control policies on slim cigarette consumption.
\end{abstract}




\section{Keywords}

Slim Cigarettes, Tobacco Control, Tobacco Taxation, China

\section{Introduction}

According to the 2012 draft European Union-Tobacco Product Directive, slim cigarettes are defined as cigarettes with a diameter of less than $7.5 \mathrm{~mm}$ [1]. Traditionally, all cigarettes with a circumference of less than $24 \mathrm{~mm}$ (equivalent to $7.6 \mathrm{~mm}$ in diameter, approximately equal to the European standard) were regarded as slim cigarettes in China. In 2014, China's State Tobacco Monopoly Administration (STMA) put forward a new standard for slim cigarettes. According to the new standard, slim cigarettes are defined as cigarettes with a circumference of $17 \pm 1 \mathrm{~mm}$, equivalent to $5.1-5.7 \mathrm{~mm}$ in diameter. And STMA also required that the price of newly developed slim cigarettes could not be lower than the price of Class B regular cigarettes, while the tar content level should be no more than $8 \mathrm{mg}[2]$.

Slim cigarettes were designed and marketed as women-specific tobacco products when first developed almost a half century ago [3] [4]. However, this study found no significant correlations between the market share of slim cigarettes and the smoking prevalence rates, especially the smoking prevalence rates among females [5]. Some existing literature has studied the perception of different smokers with respect to slim cigarettes and the implications for the smoking epidemic and tobacco control. A number of studies using focus groups and in-depth interviews found that slim cigarettes were viewed as favorable, attractive, or multiple other positive connotations by adolescents [6] and young females [7] [8] and that the slimmer diameter might communicate messages of being weaker tasting and less harmful [6]. Studies also showed that slim cigarettes were more likely to be perceived as less harmful [9] [10]. In contrast, one study showed that regular diameter cigarettes were perceived as more attractive and of higher quality than slim ones by young adult smokers, especially males [11]. No matter, sales of slim cigarettes have been growing much faster than sales of regular cigarettes, comprising a growing share of the global cigarette market in recent years.

China is the largest tobacco consumer and producer in the world, accounting for $44 \%$ of the world's total cigarette consumption and $43 \%$ of the world's total tobacco leaf production [12]. China began to pay attention to slim cigarettes in the 1970s [13], and produced the first slim cigarette with a circumference of 17 $\mathrm{mm}$ in 2006 [14]. With the increasing pressure of tobacco control, STMA regarded slim cigarettes as a strategic market segment to target young adult smokers pursuing fashion and elegance, and a key tool to lower cost and increase benefit [15]. A number of measures were required to accelerate slim cigarette development, production, and marketing [16]. Sales of slim cigarettes reached 
68,945 million sticks in 2016 [17], 191.5 times the sales in 2006 (360 million sticks) [18], and 4.9 times the sales in 2014 (13,980 million sticks) [15], making China the largest slim cigarette market in the world [19].

In May 2015, China raised cigarette taxes allowing the increase to be passed along to the retail price. The new policy included: 1) an increase in the ad valorem tax rate on cigarettes at the wholesale level from $5 \%$ to $11 \%$, and 2 ) an additional specific excise tax of 0.10 RMB per pack of cigarettes at the wholesale level [20]. The tax increases apply to all type of cigarettes, including slim cigarettes.

However, few studies have offered a market analysis of the slim cigarette industry in China and its implications for tobacco control. To our knowledge, no published literature explores the correlation between tobacco control policies and slim cigarette consumption. This paper aims to address this gap by studying: 1) the trends in market share development of slim cigarettes in China, 2) the impact of the 2015 tobacco tax increase on the consumption of slim cigarettes, and 3) the potential substitution of slim cigarettes for regular cigarettes in China.

\section{Methods}

\subsection{Data}

We used the monthly data on cigarette sales between January 2014 and June 2017, a total of 42 months of data reported by the China National Tobacco Corporation (CNTC). Sales data, collected by the CNTC, are based on retailers' purchases of cigarettes from CNTC.

The share of slim cigarette sales rose from $0.42 \%$ in January 2014 to $5.21 \%$ in June 2017, a twelve-fold increase. The value of the share increased from $0.58 \%$ to $7.13 \%$ because of the higher average price of slim cigarettes, a 12.3 times increase. Figure 1 describes the growing trend of the slim cigarette market share over the 42-month period studied.

Not only did sales of slim cigarettes increase during the period, but the number of products also increased rapidly. Between 2012 and 2016, the number of brands grew almost 14 times, from 8 to 111 [15] [17] [21].

The average price of slim cigarettes between January 2014 and June 2017 was 16.87 RMB per pack, 49\% higher than the average price of regular cigarettes-11.32 RMB per pack. CNTC has classified 5 grades of cigarettes according to their allocation prices: Grade A (10 RMB/pack or more), Grade B (7 - 10 RMB/pack), Grade C (3 - 5 RMB/pack), Grade D (1.65 - 3 RMB/pack), Grade E (less than $1.65 \mathrm{RMB} /$ pack) [22]. Slim cigarettes belong to the top grade price range. However, over the time studied, the price range of the slim cigarettes stabilized between 16 and 18 RMB per pack, while the price range for regular cigarettes was wider, 10 to $14 \mathrm{RMB}$ per pack (Figure 2). While the price of slim cigarettes is higher than the price of regular cigarettes, over time, the ratio between slim and regular cigarette prices has been narrowing. 


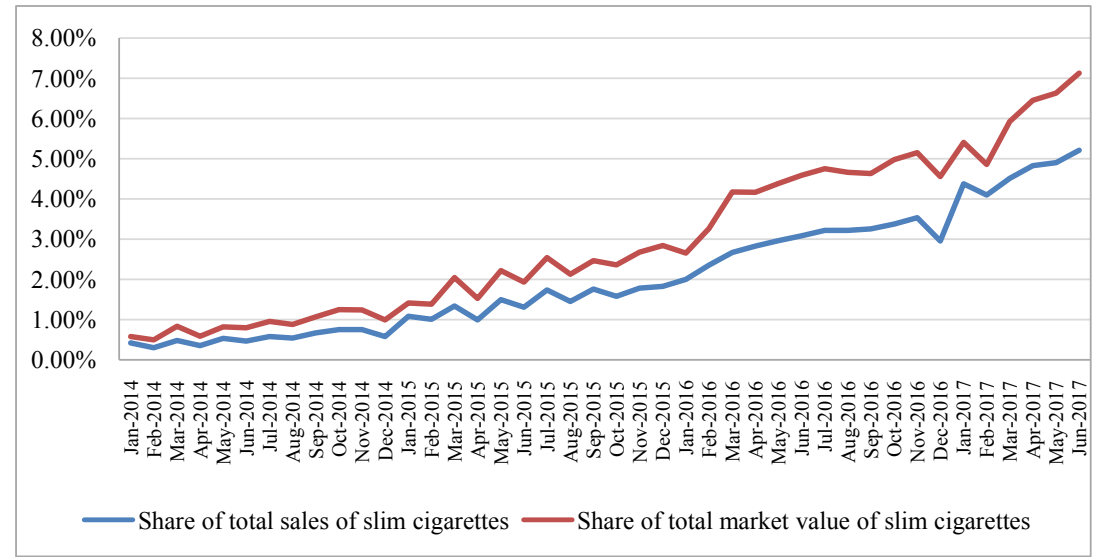

Figure 1. Market shares of slim cigarettes by sales and market value, January 2014 through June 2017.

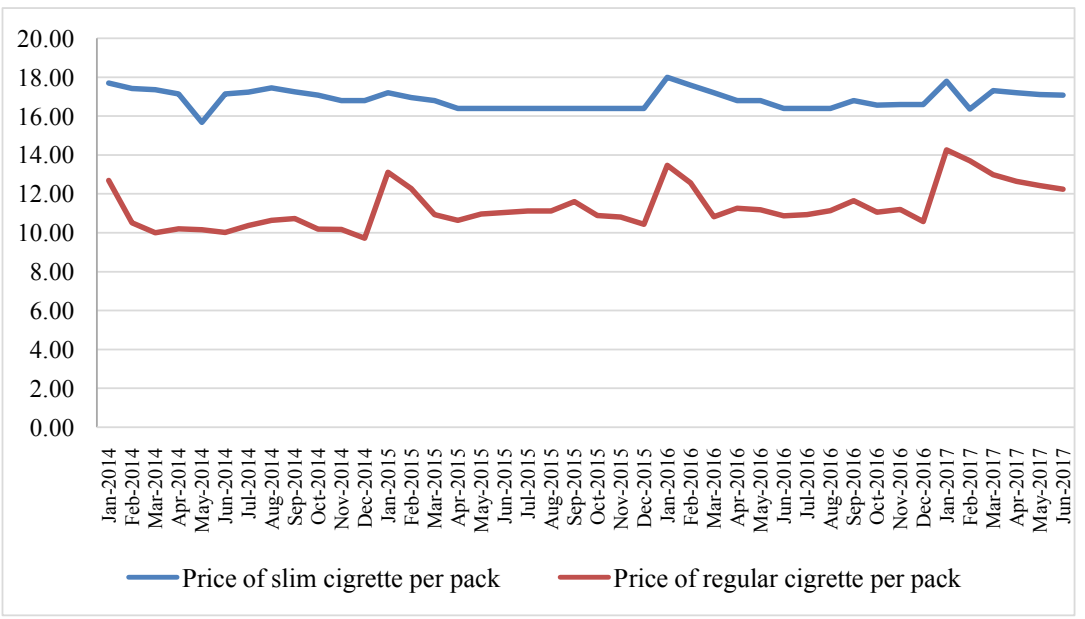

Figure 2. The prices of slim cigarettes and regular cigarettes in RMB, January 2014 through June 2017.

\subsection{Statistical Analysis}

Two models are estimated to determine the impact of tax policy on the consumption patterns of slim cigarettes in China: Market share model and a consumption model. Two dependent variables are used to measure the consumption pattern: Shares of slim cigarette sales as a percent of total cigarette sales and the average packs of slim cigarettes consumed each month per capita. Per capita data are used to adjust for the effect of population growth on cigarette sales [23]. Segmented regression analysis of interrupted time series is an effective statistical method to evaluate longitudinal effects of time-delimited interventions. In both models, two parameters are estimated for each intervention: Level and trend. The level parameter (dummy variable for tax variables, 1 after May 2015 and zero before May 2015) represents the immediate effect of the tax on the outcome. The time trend and interaction with the tax variable is the rate of change, which measures the gradual change of the outcomes due to the intervention. The price ratio of slim vs. regular cigarettes variable measures the effect of the relative 
price of slim cigarettes and regular cigarettes on slim cigarette consumption. The time trend and monthly pattern of sales are adjusted by the AR parameters in AUTOREG procedure. The results of the two models are presented in Table 1 and Table 2.

Table 1. The impact of the 2015 tobacco tax increase on the market share of slim cigarettes.

\begin{tabular}{cccc}
\hline \multicolumn{4}{c}{ Maximum-Likelihood Estimates of the Model } \\
\hline Log Likelihood & 15.690 & Observations & 42 \\
Total $\mathrm{R}^{2}$ & 0.9875 & \\
Transformed ${ }^{2}$ & 0.9913 & \\
\hline & Parameter Estimates & Pr $>|\mathrm{t}|$ \\
Variable & Estimate & $\mathrm{t}$ Value & 0.0019 \\
Intercept & 1.4300 & 3.37 & $<0.0001^{* * *}$ \\
Time (in month) & 0.0534 & 5.11 & 0.0671 \\
Tax Policy & -0.2117 & -1.89 & $<0.0001^{* * *}$ \\
Time after Tax Policy & 0.0891 & 8.36 & $0.0044^{* *}$ \\
Price Ratio & -0.7536 & -3.05 & 0.0468 \\
AR2 & -0.2854 & -2.06 & 0.0167 \\
AR5 & 0.3545 & 2.52 & 0.0106 \\
AR6 & 0.4145 & 2.70 & \\
\hline
\end{tabular}

${ }^{* *}$ Significant at $0.001,{ }^{*}$ Significant at 0.01 .

Table 2. The impact of the 2015 taxation policy on packs of slim cigarettes consumed each month per capita.

\begin{tabular}{cccc}
\hline \multicolumn{4}{c}{ Maximum-Likelihood Estimates of the Model } \\
\hline Log Likelihood & 82.009 & Observations & 42 \\
Total $\mathrm{R}^{2}$ & & 0.9049 & \\
Transformed $\mathrm{R}^{2}$ & Parameter Estimates & \\
\hline & Estimate & $\mathrm{t}$ Value & \\
Variable & 0.3264 & 3.97 & 0.0003 \\
Intercept & 0.0024 & 1.71 & 0.0951 \\
Time (in month) & -0.0125 & -0.82 & 0.4187 \\
Tax Policy & 0.0069 & 4.68 & $<0.0001^{* * *}$ \\
Time after Tax Policy & -0.1851 & -3.86 & $0.0005^{* * *}$ \\
Price Ratio & 0.6048 & 4.43 & $<0.0001$ \\
AR1 & & & \\
\hline
\end{tabular}

$* * *$ Significant at 0.001 . 


\section{Results}

The estimated results show that the immediate effects of the 2015 tax policy change (dummy variable) are not significant even at a significance level of 5\% in either model, perhaps indicating that neither consumers nor the tobacco industry had time to adjust to the taxation policy change immediately.

Table 1 shows that the dependent variable of market share of slim cigarettes initially decreased by $0.2117(\mathrm{p}=0.0671)$ when the 2015 tobacco tax was implemented, indicating a $0.02 \%$ share reduction. Then, the market share began to increase beyond the third month after the tax increase $(0.0891 \times 3=0.2673)$. After the tax increase, the growth of the shares was 1.6 times the normal increase with time (0.0891 versus 0.0543$)$. The higher the price ratio, the lower the sales market share of the slim cigarettes, indicating a negative coefficient suggesting that slim cigarettes are a substitute for regular cigarettes and that smokers do take into account the price differences between slim and regular cigarettes.

Figure 3 which presents the predicted value and the actual value of market shares for slim cigarettes, shows that by the second quarter of 2017, controlling for the price difference between slim and regular cigarettes, the 2015 taxation policy had helped slim cigarettes gain an additional share of the sales market, from $2.58 \%$ to $4.60 \%$, a $78 \%$ increase.

We also estimated the market value share, which is the total value of slim cigarettes compared to the values of the total cigarette market. We found similar time patterns with the sales market share. The value share increases with time, and the 2015 taxation policy brought even higher value share, and the higher the price ratio of slim versus regular cigarettes, the bigger the market share. It is estimated that by the second quarter of 2017, the additional market share for slim cigarettes was $2.7 \%(6.28 \%-3.58 \%)$, attributable to the tax increase and the unmeasured effect of smoke-free policies.

We also estimated the regression model for the average slim cigarette consumption over time. Table 2 presents the results.

The consumption model had similar results to the market share model. The number of packs of slim cigarettes consumed increased significantly.

Table 2 shows that initially, the 2015 tobacco tax had no statistically significant effect on the sales of slim cigarettes. In fact, over time, the post-tax time period showed a continual increase in slim cigarettes sales. And after the tax increase was announced, sales of slim cigarettes increased almost three times the normal trend of increasing. By the second quarter of 2017, the increase in sales of slim cigarettes was almost twice the regular growth in consumption $(0.17$ packs to 0.33 packs) (Figure 4 ).

The estimates show that the growth of slim cigarette consumption is not related to the GDP growth, indicating a change in the social norm related to smoking as smokers were more likely to pick up slim cigarettes as well as changes in the production and marketing strategies of the tobacco industry. A time effect shows that the policy change in 2013 as well as the taxation policy in 


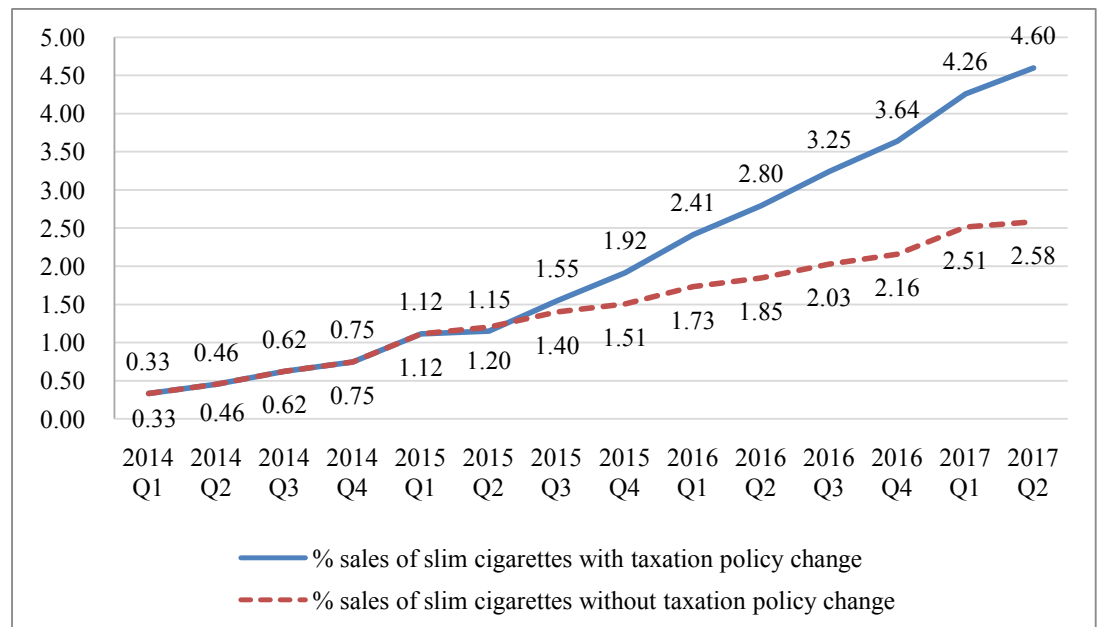

Figure 3. The predicted and actual market shares of slim cigarettes, the first quarter of 2014 through the second quarter of 2017. Note: Q1 means the first quarter, and so on.

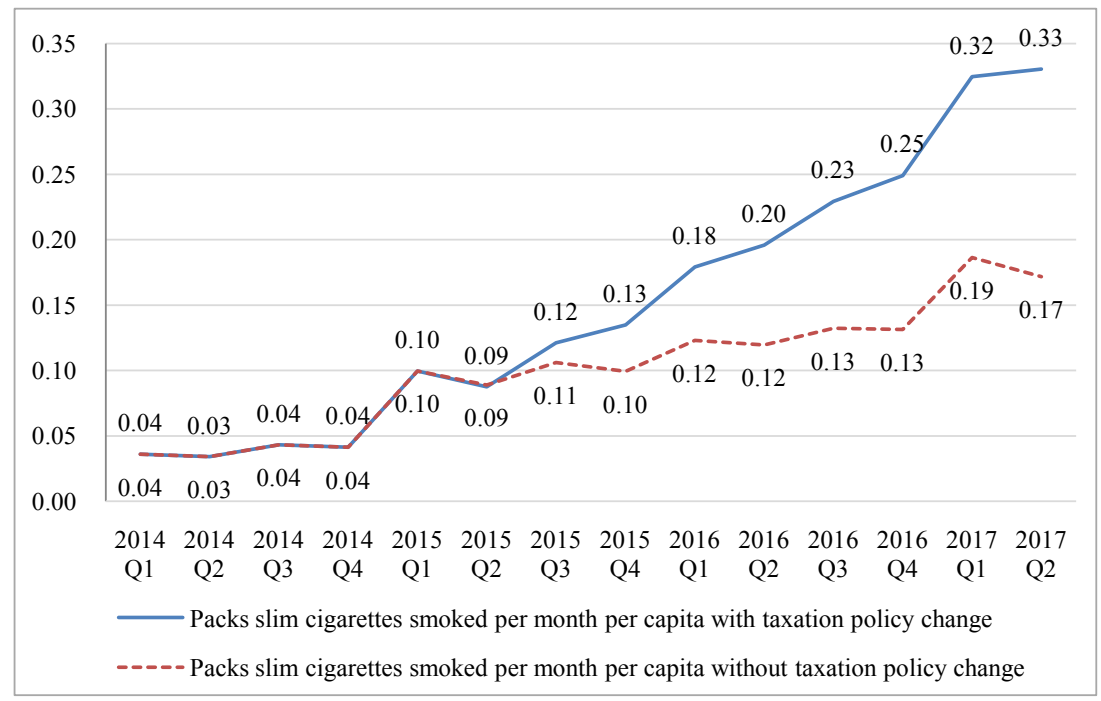

Figure 4. The predicted and actual consumption of slim cigarettes per month per capita, the first quarter of 2014 through the second quarter of 2017.

2015 helped this changing trend. The increase of slim cigarette consumption in China is a trend now, and the taxation, as well as unmeasured smoke-free policies, speeded up the growing trend toward slim cigarettes. However, we also see the narrowing price range between slim and regular cigarettes, a trend that will reduce slim cigarette sales.

\section{Discussions}

With the speed of domestic economic growth in China slowing down and tobacco sales declining or remaining stable, sales of slim cigarettes have maintained a rapid growth; the price of slim cigarettes tends to be rising; the number of brands and the product regulations are gradually growing. CNTC has taken a number of measures to accelerate slim cigarette development, including in- 
creased investment in technology and research. Slim cigarettes are quite likely to become the focus of the promotion and sales of CNTC, and slim cigarette consumption in China will continue to grow rapidly. A survey carried out in 2016 by a branch of CNTC showed that the consumers of slim cigarettes were mainly between 25 and 45 years old (66\%); more specifically, 31\% were between $25 \%$ and $35 \%$, and $35 \%$ were between 36 and 45 [24]. Understanding the ramifications of the rapid growth of slim cigarettes on tobacco control in China is very critical. In fact, by 2017, the market shares of slim cigarettes in China had reached $5.03 \%$ of sales and $7.21 \%$ of revenue, growing by $4.93 \%$ and $7.05 \%$, respectively, from 2012 [25]. Some research has found that slim or super-slim cigarettes are more attractive for adolescents because the slimmer diameters communicate a weaker tasting and by assumption, less harmful product.

The findings of this paper show that the 2015 tobacco tax increase had a minimal or only a short-term impact on reducing sales of slim cigarettes, perhaps because of the special design features of the product and CNTC's promotion of slim cigarettes as a healthier and fashionable new type of cigarette. The taxation policy has resulted in more aggressive marketing of slim cigarettes by the tobacco industry, and more smokers have changed their smoking habits by converting to slim cigarettes. The other possibility is that the overall tax increase, which was only $10 \%$ of the retail prices, was not significantly large enough to deter smokers from consuming their usual number of cigarettes [20]. Since slim cigarettes are a substitute for regular cigarettes, it will be important to have a much higher tax increase in the next round of tobacco tax adjustments.

Different from the previous belief that the slim cigarette is the choice of female smokers, slim cigarettes, in fact, are becoming the norm for consumers in general. In China, the prevalence of female adults who smoke is $2.7 \%$ and male smoking prevalence is $52.1 \%$ [26]. Female smokers account for about $4.8 \%$ of the total smokers. It is hardly likely that female smokers all picked up slim cigarettes. In fact, a recent report showed that many male smokers have begun to smoke slim cigarettes [27].

Many public health experts think that the harm of smoking slim cigarettes on human health is no less than the harm from smoking regular size cigarettes [28] [29], although researchers examining the influence of slim cigarettes on health have not yet reached a unanimous conclusion. Moreover, the popularity of slim cigarettes will have a great negative effect on tobacco control efforts. Research also shows that the slim cigarette market share has no significant relationship to the smoking rate [5]. At present, the slim cigarette industry in China is developing rapidly. Therefore, more empirical research is urgently needed comparing slim cigarettes with regular cigarettes in terms of the harm to human health, and whether slim cigarettes will reduce tobacco consumption or attract more people to smoke [6].

\section{Conflicts of Interest}

The authors declare no conflicts of interest regarding the publication of this paper. 


\section{References}

[1] European Commission (2012) Proposal for a Directive of the European Parliament and of the Council on the Approximation of the Laws, Regulations and Administrative Provisions of the Member States Concerning the Manufacture, Presentation and Sale of Tobacco and Related Products. European Commission, Brussels, Belgium.

[2] Yan, J. (2015) Calm Thinking on the Blue Ocean of Slim Cigarettes Development (in Chinese). China Tobacco.

http://www.tobaccochina.com/revision/takematter/wu/20154/2015326133010_6677 76.shtml

[3] Carpenter, C.M., Wayne, G.F. and Connolly, G.N. (2005) Designing Cigarettes for Women: New Findings from the Tobacco Industry Documents. Addiction, 100, 837-851. https://doi.org/10.1111/j.1360-0443.2005.01072.x

[4] Dewhirst, T., Lee, W.B., Fong, G.T. and Ling, P.M. (2016) Exporting an Inherently Harmful Product: The Marketing of Virginia Slims Cigarettes in the United States, Japan, and Korea. Journal of Business Ethics, 139, 161-181. https://doi.org/10.1007/s10551-015-2648-7

[5] Slater, A. (2016) Cross-Sectional Relations between Slim Cigarettes and Smoking Prevalence. Beiträge zur Tabakforschung International/ Contributions to Tobacco Research, 27, 75-99. https://doi.org/10.1515/cttr-2016-0010

[6] Ford, A., Moodie, C., MacKintosh, A.M. and Hastings, G. (2014) Adolescent Perceptions of Cigarette Appearance. European Journal of Public Health, 24, 464-468. https://doi.org/10.1093/eurpub/ckt161

[7] Moodie, C., Ford, A., Mackintosh, A. and Purves, R. (2015) Are All Cigarettes Just the Same? Female's Perceptions of Slim, Coloured, Aromatized and Capsule Cigarettes. Health Education Research, 30, 1-12. https://doi.org/10.1093/her/cyu063

[8] Hoek, J. and Robertson, C. (2015) How Do Young Adult Female Smokers Interpret Dissuasive Cigarette Sticks? Journal of Social Marketing, 1, 21-39.

[9] Bansal-Travers, M., Hammond, D., Smith, P. and Cummings, K.M. (2011) The Impact of Cigarette Pack Design, Descriptors, and Warning Labels on Risk Perception in the U.S. American Journal of Preventive Medicine, 40, 674-682. https://doi.org/10.1016/j.amepre.2011.01.021

[10] Carpenter, C.M., Wayne, G.F. and Connolly, G.N. (2007) The Role of Sensory Perception in the Development and Targeting of Tobacco Products. Addiction, 102, 136-147. https://doi.org/10.1111/j.1360-0443.2006.01649.x

[11] Borland, R. and Savvas, S. (2013) Effects of Stick Design Features on Perceptions of Characteristics of Cigarettes. Tobacco Control, 22, 331-337.

https://doi.org/10.1136/tobaccocontrol-2011-050199

[12] Eriksen, M., Mackay, J., Schluger, N., Gomeshtapeh, F.I. and Drope, J. (2015) The Tobacco Atlas: Fifth Edtion. American Cancer Society Inc., Atlanta, GA.

[13] (1974) Symposium on Slim Cigarettes Production (in Chinese). Tobacco Science and Technology, 1, 24.

[14] Wang, B. (2015) Study on the Development Strategy of Domestic Slim Cigarettes. Modern Business Trade Industry, 2, 4-5.

[15] Zuo, Y. (2015) Review of the Development of Slim Cigarettes in 2014 (in Chinese). China Tobacco, 5, 60-61.

[16] Yang, H. (2018) Cultivate a New Outstanding Segment in Development of Chinese-Style Cigarettes (in Chinese). East Tobacco News. 
[17] China Cigarette Sales and Marketing Corporation (2017) Analysis of China's Cigarettes Market in 2016 (in Chinese). China Tobacco, 5, 62-65.

[18] Bai, Y., Cao, C. and Li, D. (2015) Brands Competition and Market Expansion of Slim Cigarettes in China (in Chinese). China Tobacco, 11, 38-40.

[19] Westrock (2017) China Overtook Korea as the Largest Slim Cigarettes Market for the First Time Beijing: China Tobacco.

http://www.echinatobacco.com/html/site27/jycz/86055.html

[20] Hu, T.W., Zhang, X. and Zheng, R. (2015) China Has Raised the Tax on Cigarettes: What's Next? Tobacco Control, 25, 609-611. https://doi.org/10.1136/tobaccocontrol-2015-052534

[21] China Cigarette Sales and Marketing Corporation (2016) Overview of China's Cigarettes Market Development in 2015 (in Chinese). China Tobacco, 5, 65-69.

[22] Zheng, R., Wang, Y. and Hu, X. (2016) Tobacco Tax: Theory, System Design, and Policy Practice (in Chinese). Financial Minds, 1, 5-30.

[23] Hu, T.W., Sung, H.Y. and Keeler, T.E. (1995) Reducing Cigarette Consumption in California: Tobacco Taxes vs an Anti-Smoking Media Campaign. American Journal of Public Health, 85, 1218-1222. https://doi.org/10.2105/AJPH.85.9.1218

[24] Wang, W. (2017) Strategies to Cultivate Slim Cigarettes Brands: Product, Price, Place and Promotion (in Chinese). East Tobacco News.

[25] Ling, C. (2018) Digest of Chengxing Ling's Report at 2018 National Tobacco Conference (in Chinese). China Tobacco, 3, 15-20.

[26] Yang, Y., Nan, Y., Tu, M., Wang, J., Wang, L. and Jiang, Y. (2016) Major Finding of 2015 China Adults Tobacco Survey (in Chinese). Chinese Journal of Health Mangement, 10, 85-87.

[27] Which High-End Slim Cigarettes Taste Best, and Why Smokers of Slim Cigarettes Get More and More? (2017) (in Chinese). https://www.cnxiangyan.com/zhishi/2467.html

[28] Siu, M., Mladjenovic, N. and Soo, E. (2013) The Analysis of Mainstream Smoke Emissions of Canadian 'Super Slim' Cigarettes. Tobacco Control, 22, e10. https://doi.org/10.1136/tobaccocontrol-2012-050450

[29] Ashley, M., Sisodiya, A., McEwan, M., McAughey, J. and Prasad, K. (2011) Comparison of Mouth Level Exposure to 'Tar' and Nicotine in Smokers of Normal and Superslim King Size Cigarettes in Romania. Beiträge zur Tabakforschung Internationall Contributions to Tobacco Research, 24, 277-288.

https://doi.org/10.2478/cttr-2013-0908 